\title{
PRODUÇÃO SOCIAL, HISTÓRICA E CULTURAL DO CONCEITO DE JUVENTUDES HETEROGÊNEAS POTENCIALIZA AÇÕES POLÍTICAS
}

PRODUCCIÓN SOCIAL, HISTÓRICA Y CULTURAL DEL CONCEPTO DE JUVENTUDES HETEROGÉNEAS POTENCIALIZA ACCIONES POLÍTICAS THE SOCIAL, HISTORICAL AND CULTURAL CONCEPT PRODUCTION OF THE HETEROGENEOUS YOUTH(S) ENHANCES POLITICAL ACTIONS

\author{
Alcimar Enéas Rocha Trancoso e Adélia Augusta Souto Oliveira \\ Universidade Federal de Alagoas, Maceió/AL, Brasil
}

\begin{abstract}
RESUMO
Conceitos são definidos no contexto social, cultural, histórico, constituindo-se no ambiente sociopolítico. O campo social, espaço onde a ação do homem tem significado e produz sentido, é o lócus da produção de conceitos. A metassíntese realizada analisou 37 artigos científicos e 176 teses e dissertações que discutem o conceito de juventude, do período de 2007 a 2011, encontradas através do banco de teses da CAPES e da biblioteca eletrônica SCIELO pelo Google Acadêmico. Resultados indicam que o conceito de juventudes, expresso pelas distintas forças políticas, é um exemplo do poder mobilizador do ato de conceituar, evidenciado na contemporaneidade. A perspectiva da lógica linear e fásica da vida convive com a heterogeneidade, expressando assim um campo propício para as distintas perspectivas e posturas teóricas. A psicologia social crítica é desafiada a fortalecer presença nos circuitos da produção de conceitos, promovendo reflexão significativa e elementos de transformação.
\end{abstract}

Palavras-chave: conceito; metassíntese; juventudes; ação política.

\section{RESUMEN}

Los conceptos se definen en el contexto cultural, social, historico, convirtiéndose en el ambiente sociopolítico. El espacio del campo social en que la acción humana tiene un significado y produce sentido, es el lócus de la producción de los conceptos. A meta-síntesis realizada analizó 37 artículos científicos y 176 tesis y disertaciones que tratan sobre el concepto de juventud, del período de 2007 a 2011, encontradas en la base de tesis CAPES y en la biblioteca electrónica SciELO por Google Scholar. Los resultados indican que el concepto de los juventudes, expresada por diferentes fuerzas políticas, es un ejemplo del poder de movilización del acto de la conceptualización, evidenciado en la época contemporánea. La perspectiva de la lógica lineal y fásica de la vida coexiste con la heterogeneidad, expresando así un campo favorable para los diferentes puntos de vista y posiciones teóricas. La psicología social crítica tiene el reto de fortalecer la presencia en el circuitos de producción de los conceptos, promoviendo reflexión significativa y elementos de transformación.

Palabras clave: concepto; metasíntesis; los jóvenes; acción política.

\begin{abstract}
Concepts are social, cultural and historical definitions, whose constitutive process is within the sociopolitical environment. The social field, is the locus to concepts production. The metasynthesis carried, analyzed 37 papers and 176 thesis and dissertations that discuss about youth concept, published 2007-2011 period, found through the CAPES thesis database and the electronic library SCIELO by Google Scholar. Results indicate youth concept, expressed by different political forces, is an example of the mobilizing power of the conceptualizing act, evidenced in contemporary times. The linear and phasic perspective of the life, coexists with heterogeneity, thus expressing a field conducive to the different perspectives and theoretical positions. The social and critical Psicology is challenged to strengthen presence in the circuit of concepts production, promoting meaningful reflection and transformation elements.
\end{abstract}

Keywords: concept; metasynthesis; youths; political action. 


\section{Introdução}

As palavras são definidas no contexto cultural e datadas historicamente. Os conceitos sobre as juventudes e suas transform(ações) são questões que motivam a reflexão neste trabalho. O poder da palavra está no processo de sua constituição, pois, sendo sua base a ação, converte-se em um nível maior, subordina-a ao tempo em que se transforma em ato. A palavra como signo que comunica e representa, que "permite agir sobre as pessoas e sobre si mesmo, produzindo mudanças nelas e em si próprio. Basta lembrar o poder da palavra sobre as pessoas. Ela comanda suas ações" (Pino, 2005, p. 148). As partes da díade ação - palavra estão intrinsecamente relacionadas na medida em que a segunda, ao intelectualizar-se e desenvolver-se, se faz a partir da primeira, subordinando-a.

Desse modo, as palavras e as ações podem mudar o trajeto da existência, possibilitam a vida e definem a morte. Por isso, subverter a ordem mundial homogênea - de uma inclusão perversa administrada pelos grupos que se mantêm no poder - pode gestar novos fundamentos epistemológicos e ontológicos (Sawaia, 2001; Souza Santos, 1997).

Ao discutir o desenvolvimento dos conceitos científicos na infância, Vigotski (1999) apresenta e rejeita duas concepções explicativas correntes em sua época: a que os conceitos são absorvidos, assimilados pela criança, não estabelecendo eles nenhuma relação com os seus processos internos, e a que entende que há sim "um processo de desenvolvimento na mente da criança" (p. 105), mas sem diferença, "em nenhum aspecto, do desenvolvimento dos conceitos formados pela criança em sua experiência cotidiana". Diferentemente, para esse autor, os conceitos nem são aprendidos mecanicamente como que colados à mente, nem tampouco são meros pares dos conceitos espontâneos, posto que "evoluem com a ajuda de uma vigorosa atividade mental por parte da própria criança" (Vigotski, 1999, p. 107).

Entendendo que estabelecer um conceito é permitir sua generalização, ou seja, uma única explicação para uma série de coisas que se interrelacionam, esse autor atribui a este momento na história de vida da criança uma importância muito grande dentro da sua concepção dialética dos processos humanos. Através do aprendizado, os conceitos vão se constituindo uma poderosa força que direciona o desenvolvimento da criança "determinando o destino de todo seu desenvolvimento mental" (p. 107). Os conceitos científicos parecem constituir o canal por onde a consciência e o domínio das coisas, da realidade, de si mesmo se desenvolvem, podendo a criança dominar ou se subordinar a um conceito.

O referido autor trata da formação de conceitos, a partir do processo de desenvolvimento na criança do pensamento e da linguagem. Desse modo, podemos levar em consideração o princípio de que os conceitos, dentro do processo de aprendizagem humana, tornamse determinantes nas relações intra e intersubjetivas estabelecidas. Como base em simples observação de dados históricos, são vastos os exemplos de grandes mobilizações sociais conseguidas a partir da difusão de uma ou conjunto de ideias: guerras, revoltas, discriminações, racismos, consumo de produtos mediado pelo consumo de imagens e ideias.

Daí a importância de se perguntar: em um processo sócio-histórico, como os conceitos são produzidos? Como o ato de conceituar se relaciona com a atividade humana, concebida de uma forma generalizada, e, dentro dela, influencia a relação dos distintos campos do conhecimento, as escolhas do cotidiano, a ação política?

O conceito de juventude, o modo como é expresso pelas distintas forças políticas, é um exemplo do poder mobilizador do ato de conceituar. Além disso, traz em si a complexidade típica das significações que se transformam à medida que a própria realidade é transformada. A não ser por imposição, torna-se impossível um conceito unívoco para a juventude, dada a sua complexidade ampliada pela elasticidade que adquire na contemporaneidade, que desvincula a idade do sentir-se jovem, reforça a importância de se pensar as questões biológicas, psíquicas, sociais e culturais do desenvolvimento humano.

Nesse contexto, o tema juventude tem adquirido destaque crescente nos últimos anos e vem sendo pesquisado a partir de diferentes perspectivas teóricas e metodológicas. Podem ser listados pelo menos quatro aspectos, às vezes antagônicos, não hierárquicos, que têm contribuído para que os estudos sobre juventude estejam em evidência no Brasil e no mundo.

Primeiro, o fortalecimento da perspectiva de que é uma etapa do ciclo da vida onde culmina o processo de socialização, bem como prepara o indivíduo para a produção e reprodução da vida e da sociedade (Abramo, 2005), e isso possui um forte apelo em uma sociedade como a ocidental, erigida sobre pilares capitalistas em que a entrada no mundo do trabalho/emprego ocupa o centro do projeto de vida. Esse aspecto possui uma relação circular de fortalecimento mútuo com as políticas públicas, especialmente as de educação.

Segundo, em outra direção, refere-se ao fato de a juventude estar deixando de ser vista e representada 
como uma etapa da vida e se convertendo em uma condição a ser alcançada e/ou conservada pelas pessoas, independentemente da idade que possuem (Kafrouni, 2009; Spaziro \& Resende, 2010), fenômeno esse conceituado sob a alcunha de juvenilização.

Terceiro, por características que o jovem adquiriu - ou lhe foram atribuídas - na contemporaneidade, vinculadas aos conceitos de protagonismo e resistência, tem sido visto como um barômetro das novas tendências (Feixa \& Leccardi, 2010).

Por último, as reflexões sobre o desenvolvimento da capacidade de resistência do jovem apoiado no aumento do capital social e no fortalecimento do sentimento de pertença (León, 2005), que vêm sendo identificados como formas concretas de possibilidade de revolução, de mudança social a partir da juventude, se apresentam também como um aspecto difusor dos estudos sobre juventude.

Some-se a esses aspectos, no campo da aplicabilidade de ações, o fato de o Estado brasileiro, em 2005, elevar o jovem a uma condição de maior visibilidade no campo da política pública, ao estabelecer um setor no seu corpo administrativo para cuidar das questões referentes a esse grupo. Assim a Lei Federal que cria o Conselho Nacional de Juventude (CNJ), vinculado à Secretaria Geral da Presidência da República, destaca que esse conselho deve "formular e propor diretrizes da ação governamental voltadas à promoção de políticas públicas de juventude, fomentar estudos e pesquisas acerca da realidade socioeconômica juvenil e o intercâmbio entre as organizações juvenis nacionais e internacionais" (Lei n. 11.129, 2005, pp. 1-2).

O conteúdo da referida Lei dá uma ideia de como o tema juventude estará sendo tratado pelo poder público federal. Tema cuja relevância o coloca como alvo da criação de políticas públicas específicas, cuja necessidade de conhecimento influenciará a destinação de recursos para pesquisas acadêmicas, e que será transversal dentro das ações ministeriais. A juventude está sendo vista no âmbito da política pública como um grupo que, em si mesmo, possui relevância estratégica para o país no momento presente, especialmente pela parcela da população que atende à qualificação etária básica para ser considerada jovem segundo essa Lei e as implicações dela decorrentes: dados do censo brasileiro de 2010 fornecidos pelo Instituto Brasileiro de Geografia e Estatística (IBGE) informam que aproximadamente $17,94 \%$ possuem de 15 a 24 anos de idade e em torno de $26,91 \%$ possuem de 15 a 29 anos de idade.

As distintas abordagens presentes no campo da discussão teórica também podem ser observadas na apropriação e uso conceitual do termo juventude por organismos internacionais, como a Organização das Nações Unidas (ONU), o governo brasileiro e organizações não governamentais. Para os dois primeiros, percebe-se que prevalecem os argumentos da juventude como uma fase da vida delimitada por uma idade de entrada e de saída, apesar de estabelecerem parâmetros etários distintos para definição do ser jovem (Furiati, 2010). As organizações não governamentais utilizam, ao focalizarem suas intervenções nos problemas sociais que afetam os jovens - incluindo, ainda que com menor intensidade, o fomento do protagonismo juvenil (Abramo, 1997) -, um conceito não exclusivamente etário, apesar dessa dimensão também ser considerada nas definições utilizadas.

Todos esses aspectos e as questões práticas referentes à juventude trazem certa dificuldade e tensão no processo de conceituação. Para Sposito (2002), uma forma de superar essas dificuldades na definição do conceito de juventude reside em reconhecer que a própria definição da categoria juventude encerra um problema sociológico passível de investigação, na medida em que os critérios que a constituem são históricos e culturais. Reconhecer juventude como problema sociológico significa aceitá-la como noção socialmente variável. Varia ao longo do tempo entre sociedades e dentro dos grupos de uma mesma sociedade. Um exemplo disso, para Pais (1990), por exemplo, é a adolescência, que, apesar de a puberdade ser universal, só aparecer como fase da vida a partir de problemas e tensões a ela associados.

No Brasil, a discussão mais intensa sobre juventude é relativamente recente (Abramo, 2005; Borges, 2010), considerando que é "somente por volta de 1995, que a 'percepção da juventude para além da adolescência em risco, numa direção, e para além dos setores da classe média, em outra direção' tomaram força" (Borges, 2010, p. 40).

O presente artigo pretende, a partir da abordagem sócio-histórica de Vigotski, refletir a produção de conceitos, tomando a heterogeneidade das concepções de juventude como potencialização da ação política. $O$ ato de conceituar é visto como fundamental tanto para a apreensão da realidade como para estabelecer uma ação sobre ela. É fruto das relações socioculturais, influenciando as escolhas do cotidiano, a ação política das pessoas, e, no universo acadêmico, a relação entre os distintos campos do conhecimento. A produção de um conceito não se dá de forma neutra, de modo a esclarecer a verdade sobre as coisas, antes revela um olhar a partir de uma janela. Quanto mais esse olhar se aproximar dessa janela, mais o campo de visão se abre; 
no movimento contrário, esse campo se restringe, podendo ambos significar tanto a diminuição como o aumento das possibilidades de se enxergar com maior precisão um objeto específico. O eixo de argumentação para essa articulação é o sujeito constituído a partir de sua inserção cultural. Desse modo, produzir conceitos, a forma de apropriar-se deles e de criar modos para nomear a realidade norteou as leituras, reflexões e articulações que se apresentam a seguir.

\section{Método}

As reflexões aqui apresentadas apoiam-se em metassíntese realizada. Essa descreve e discute o estado do conhecimento da produção acadêmica no Brasil, nas áreas de Ciências Humanas, incluindo Linguística, Letras e Artes, e das Ciências Sociais Aplicadas, sobre o conceito de juventude, divulgada no site da Coordenação de Aperfeiçoamento de Pessoal de Nível Superior (CAPES), teses e dissertações, e no Google Acadêmico, artigos científicos, publicados entre os anos de 2007 e 2011.

O Tratamento dos Dados para a seleção dos documentos realizou-se em três etapas: exploratória, para estabelecer o banco de dados inicial com o filtro restritivo - presença obrigatória da palavra juventude/ juventudes no título. Para teses e dissertações, também se utilizou a expressão conceito de juventude no resumo. Selecionaram-se 534 documentos, sendo 163 artigos científicos, 68 teses e 303 dissertações. A segunda fase, garimpagem, se caracterizou pela identificação da discussão do conceito de juventude na produção. Realizou-se a leitura dos resumos de teses e dissertações e leitura de artigos científicos. Obteve-se um tratamento dos 534 documentos com base nos critérios de identificação geral da publicação, tema, fundamentos teóricos e método utilizados (Zanella \& Titon, 2005). Foram selecionados por este procedimento 213 documentos, sendo 37 artigos, todos acessados integralmente, 35 teses e 141 dissertações. Não obtivemos texto integral de três teses e vinte e uma dissertações. Na terceira e última etapa, denominada análise de conteúdo, procedeu-se à leitura e análise, portanto, dos 189 documentos acessados integralmente ( 37 artigos científicos em sua íntegra, 32 teses e 120 dissertações, em seus capítulos sobre o conceito de juventude).

A vinculação teórica adotada nos trabalhos analisados foi identificada nos itens em que os autores apresentaram o conceito de juventude. Não se referem necessariamente, portanto, à perspectiva teórica da obra como um todo, ainda que possa haver alguma coincidência. Assim, a análise resultou em categorizações a partir das características conceituais apresentadas pelos autores sobre juventude.

\section{A formação de conceito no processo sócio- histórico}

A produção e apropriação de conceitos a partir da psicologia social crítica de base sócio-histórica permite lançar elementos para a análise e compreensão da produção do conceito de juventude. Essa escolha teórica traz implicações na compreensão do homem, da sociedade e das relações intersubjetivas. Nessa medida, o homem é visto como ser que vai se constituindo enquanto estabelece relações sociais determinadas culturalmente, em oposição à perspectiva de uma gênese autônoma do indivíduo, uma espécie de natureza humana que, como uma semente, independentemente de qualquer externalidade, se desenvolve e constitui seu verdadeiro eu.

Um pressuposto que fundamenta essa ótica do desenvolvimento autônomo é o descolamento clássico do indivíduo em relação à sociedade, da pessoa e relação ao seu meio, o que, por sua vez, pressupõe também a existência, em potencial, de uma entidade psicológica autônoma que pode ser corrompida pelos vícios da sociedade, adquiridos pelo indivíduo justamente pelo seu convívio social.

Em oposição radical a essa perspectiva, a concepção sócio-histórica tem como fundamentos a visão materialista e dialética da história, o que implica dizer que é na materialidade que se dá a produção da existência em que o homem se faz como ser humano de fato. De forma alguma, significa negar o papel fundamental dos processos físicos e bioquímicos que ocorrem no interior de cada organismo e que comandam as funções normais de cada órgão e as transformações que ocorrem no decorrer do tempo da existência biológica de cada um.

Significa sim entender que, por mais objetivos que sejam esses processos fisiológicos, eles estão submissos à intensa atividade de significação que é processada pelo homem. Ou seja, a dor, a morte, o envelhecimento, o nascimento, a maternidade, a paternidade, a excitação, dentre outras situações vivenciadas pelas pessoas no escopo do conjunto de funções usuais realizadas pelos mais variados órgãos do corpo, são experimentadas sob uma égide cultural específica. E esse é um processo que se repete indeterminadamente fundamentado na contradição dialética: o ambiente cultural e social que serve de meio para processamento da experiência pode ser transformado por esse mesmo exercício. 
Significa ainda compreender, como Pino (2005), que é a ordem simbólica que confere à atividade biológica do homem sua capacidade criadora; que a cultura nada cria, mas confere significado ao que foi criado como função ou obra da natureza, numa relação simbiótica entre ela e o simbólico. Sobre essa interação, fundamentado em Lev S. Vigotski, Pino (2005) entende que há um processo de conversão, em que as duas coisas se transformam uma na outra, cada uma delas conservando elementos próprios essenciais. Nesse sentido, não há anulação de uma em função da outra, mas transformações que ocorrem mutuamente de forma indefinida no tempo, enquanto durar a relação.

A sociedade é compreendida não em oposição ao indivíduo, mas como o ambiente criado por ele mesmo na relação com os demais seres humanos, com a natureza modificada ou não pela ação antrópica, e também com as coisas, concretas ou virtuais, produzidas. É o espaço onde a ação do homem faz e produz sentido e tem significado. Os fenômenos sociais, portanto, estão intimamente ligados às pessoas. Como ainda afirma Pino (2005), "no desenvolvimento cultural da criança cada função aparece em cena duas vezes, em dois planos. Primeiro o social, depois o psicológico, primeiro entre pessoas como uma categoria interpsicológica, depois no interior da criança como uma categoria intrapsicológica" (p. 31).

Vigotski (1999) faz uma relação interessante entre a tarefa coletiva de produzir cultura e a tarefa do coletivo de introduzir o indivíduo na cultura. Ou seja, o processo de individuação se dá sob a tutela do outro até que essa pessoa consiga, na linguagem de Pino (2005), sair de uma relação - onde as coisas não fazem sentido sem a lente mediadora do outro - para uma outra na qual o signo ocupa esse lugar e o outro se torna de fato parte necessária de uma relação de produção social e cultural. Necessária, mas não suficiente, considerando que o indivíduo torna-se agente ativo.

É nesse contexto, então, que se compreendem as relações intersubjetivas. Assim que, para além de exercer um papel coercitivo sobre o indivíduo, a sociedade, as relações sociais e a cultura produzida pelas pessoas neste ambiente de constante relação são processadas individualmente, recebem um sentido. É um processo complexo, especialmente se for considerada a questão da cultura de massas e outras perspectivas de dominação e governo de sujeitos, que também é produto histórico e cultural. O objetivo aqui é tão somente marcar esse processo de significação como uma possibilidade real do indivíduo em sociedade, como uma aptidão humana.

Como vimos, abordamos aqui, do ponto de vista da Psicologia Social Crítica de base sócio-histórica, a produção e apropriação de conceitos, especialmente apoiados na proposta de desenvolvimento histórico do ser humano na perspectiva de Vigotski (Alpizar \& Bernal, 2003; Pino, 2005; Vigotski, 1999), lançando elementos para a análise e compreensão do processo de produção de conceitos. Por sua vez, essa concepção defende a tese de produção histórica do conhecimento científico, sendo necessária a busca de sua gênese para a compreensão de fenômenos psicossociais.

Um conceito, portanto, é uma produção social. Não é um esforço exclusivo de abstração e nem um processo natural a partir da associação direta das palavras às coisas, como se a definição das mesmas já estivesse lá, cabendo ao cientista, ao sábio, apenas acessá-la de uma forma inequívoca. Segundo Vigotski (1999), a formação de um conceito está diretamente ligada à experiência vivida, não sendo "uma formação isolada, fossilizada, imutável, mas sim uma parte ativa do processo intelectual, constantemente a serviço da comunicação, do entendimento e da solução de problemas ... um processo criativo" (p. 67).

Da mesma forma, ao abordar a problemática das gerações, Mannheim (1961) trata os conceitos como instrumentos úteis para examinar o estado de um problema, sendo que os caminhos tomados para esse exame seguem, certamente, a composição de forças do determinado contexto histórico e social. Oliveira e Sawaia (2009), ao proporem "discutir a produção de conceitos sobre a infância para poder refletir a criança como sujeito real" (p. 53), reforçam a perspectiva do uso do conceito para o entendimento e a solução de problemas, como observa Vigotski (1999).

Gorczevski (2007) corrobora essa perspectiva quando considera um conceito como um dispositivo auxiliador que dispõe e/ou sustenta algo. Essa produção social transita por um caminho que pode ser compreendido como em forma de espiral, indo do ser social que produz o conceito, o homem, para o grupo social restrito ou não ao seu convívio, podendo, em época de comunicação instantânea como a atual, atingir escala global; e vindo desse grupo social complexo para os indivíduos. Souza Santos (1997), por exemplo, aborda conceitos hegemônicos cujas imagens referentes são promovidas e difundidas por "poderes hegemônicos que comandam a sociedade de consumo e a sociedade de informação" (p. 118). Esses são "teorias e imagens manipulatórias que ignoram as diferentes circunstâncias e aspirações dos povos, classes, sexos, regiões, etc., bem como as relações desiguais, de exploração e de vitimização, que tem unido às partes que compõem esta pseudototalidade" (p. 118). Nesse raciocínio, quando Vigotski (1999) afirma que o cérebro reage também às ligações 
semânticas, pode-se inferir a respeito do poder dos conceitos, das ideias, na atividade cerebral, numa conexão complexa, construtiva e criativa entre mente e corpo. Segundo Sawaia (2001), pelas afirmações de Vigotski é plausível pensar que os denominados neurotransmissores, serotonina e a dopamina, por exemplo, "são da ordem do simbólico. O significado penetra na comunicação neurológica levando o homem a agir, não em resposta a uma estrutura e organização biológica, mas a uma ideia" (p. 103).

Conceituar determinada situação, grupo ou objeto, a partir de Vigotski (1996), é considerar que o entendimento a respeito do que será conceituado deve estar sujeito aos processos criativos próprios de cada ambiente cultural; que o campo científico que servirá como meio para o desenvolvimento desse conceito não pode estar sujeito a dogmas, mas às "leis e condições gerais do conhecimento científico ... [e às] exigências objetivas que a natureza dos fenômenos objetos de estudo coloca para o conhecimento científico no estágio atual da investigação" (p. 219).

A esse respeito, Alpizar e Bernal (2003), discutindo os pressupostos de construção sóciohistórica dos conceitos, observam, porém, a possibilidade de o seu desenvolvimento estar sujeito ao que chamam de ideias fossilizadas, apoiadas em dois equívocos ainda comuns. O primeiro, de atribuir aos conceitos uma existência natural, como uma reafirmação dos fundamentos primordiais e originários da epistemologia moderna: a verdade a respeito das coisas existe e pode ser acessada através da correta dissecação do objeto estudado. Pelo contrário, o conceito é produzido em um ambiente cultural, e a cultura ou a dinâmica cultural não pode ser reificada, transformada em uma coisa sob a pena de ser colonizada, perdendo a capacidade de dar vida aos conceitos, assumindo um papel secundário nos processos de subjetivação. Os conceitos transformam e são transformados, forjam realidades e são forjados por elas; a relação é recursiva, não tautológica, mas generativa. O outro equívoco, de entender a academia como um ambiente supostamente neutro na tarefa de construção de conceitos. É ingenuidade pensar a academia como a tutora, ou a principal determinante nessa produção. Essa tarefa está presa a um emaranhado de fios que representam os mais distintos interesses.

As correntes hegemônicas de pensamento estarão sujeitas ou diretamente vinculadas às estruturas históricas e políticas, e nesse processo de disputas políticas dentro do sistema circulatório da ciência, guerras a respeito das matrizes de pensamento são travadas, mas as batalhas a respeito da conceituação dos fenômenos componentes é que vão delineando seus percursos. Assim, nessa disputa no campo político, tomando Sawaia (2001) ao discutir a dialética exclusão/inclusão, é importante usar categorias, conceitos que possam desestabilizar perspectivas epistemológicas que legitimam relações de poder, entendendo como importante a estratégia "de recuperar conceitos discriminados pelas ciências nas análises das questões sociais, e de perguntar por que eles foram excluídos ou classificados no rol do patológico e da desordem" (p. 98).

Como forma de enfrentar ou dirimir, entender arbitrariedades presentes em um processo de conceituação (Bourdieu, 1983), este pode e deve ser compreendido como uma tentativa de aproximação que, pela junção de vários conceitos, amplia a capacidade de compreensão e apreensão da realidade. Para isso, Sawaia (2001) sugere o uso do que chama conceitoprocesso, uma relação não canibal e não destrutiva entre conceitos. Ou, também, é possível pensar-se em uma versão para os conceitos, conforme a hermenêutica diatópica de Souza Santos (1997), que ajuda a operar a tradução entre saberes, consistindo em um trabalho de interpretação intercultural, identificando preocupações comuns, similares, bem como as diferentes respostas fornecidas a elas. Esse tipo de hermenêutica "é um exercício de reciprocidade entre culturas que consiste em transformar as premissas de argumentação de uma dada cultura em argumentos inteligíveis e críveis noutra cultura" (Souza Santos, 1997, p. 121).

Diante do exposto, pode ser afirmado sobre a produção de conceitos que:

1. Conceitos são formados no processo sóciohistórico, materialista e dialético. Por isso, refletem concepções que perpassam sujeitos concretos no processo material no qual são produzidos. Por serem produções humanas, estão em constante dinamicidade.

2. A produção de conceitos está diretamente ligada à capacidade criativa e de significação do homem. Isso significa dizer, dentre outras coisas, que é uma ação exclusiva do ser humano pelo uso de suas funções psicológicas superiores - atenção voluntária, memória mediada, pensamento abstrato -, conforme descreve Vigotski $(1996,1999)$.

3. A construção de conceitos é um campo, como outros, de disputa simbólica e política. Por isso, os conceitos produzidos devem ser olhados com lentes de atenção, conscientes que reproduzem um olhar dentre outros tantos possíveis, com a ressalva de que é na condição objetiva que essas várias lentes e construções possíveis devem ser provadas.

4. Ainda pensando em bases históricomaterialistas, há uma relação interdependente entre a 
abstração e a materialidade no exercício de produzir conceitos (Vigotski, 1996). O produto final, a resposta generalizadora deverá lançar luz ou solucionar uma situação concreta, que realmente atinge de forma significativa a vida de alguém ou de determinado grupo social. Não deveria estar a serviço da produção de conhecimento em função de um excesso de saber, e sim a partir de "interrogações poderosas", de um processo que fortalece a "capacidade de penetrar nos pressupostos epistemológicos e ontológicos do saber constituído, como as indagações que unem ciência e virtude, introduzindo a ordem do valor e da ética nos conceitos científicos" (Sawaia, 2001, p. 97).

\section{Juventudes heterogêneas como potencialidade na ação política}

$\mathrm{O}$ aporte teórico, fundamentado especialmente na perspectiva sócio-histórica de Lev S. Vigotski, permite afirmar que a produção do conceito de juventude possui relação direta com a materialidade social e simbólica. Ou seja, os conceitos aí compostos não são e não podem ser considerados supra-históricos, uma base estável em cima da qual a realidade é estabelecida, e a partir da qual esta mesma realidade pode ser apreendida. São construídos e significados a partir da materialidade social, econômica, cultural e histórica, com repercussões determinantes nas subjetividades.

Essa concepção desmonta a ideia de hierarquia entre áreas de conhecimento ou de níveis de importância em relação aos conceitos e seus conteúdos como algo natural, intrínseco àquilo a que o conceito se relaciona.

Dois grandes grupos se apresentam: aqueles que enfatizaram mais o biológico, a natureza humana, para a compreensão de juventude, defendendo a idade, as mudanças hormonais, a energia em excesso como marcas que permanecem e universalizam o conceito, visto que todos passam por essas mudanças que resultam em características semelhantes (Batista, 2008; Meneses, 2007). Na outra ponta, aqueles que demarcam a ênfase na raiz epistemológica da cultura, associando o conceito à experiência dos jovens, a elementos da cultura que caracterizam a juventude (Barbalho, 2011; Prata, 2009).

A nosso ver, o interpsicológico, portanto, pode contribuir e problematizar essa falsa dicotomia, pois, desde uma perspectiva sócio-histórica, localiza as mudanças biológicas dentro de um escopo cultural, trabalhando com a significação da cultura a partir dos planos sócio e microgenético. Contudo, ainda não consegue influenciar de forma significativa na produção do conceito de juventude, pois, mesmo quando o discute, os elementos culturais e biológicos aparecem separados e conflitantes (Trancoso, 2012). Portanto, converte-se em um desafio fortalecer a importância da psicologia social crítica nos circuitos estabelecidos para a produção de conceitos. Nesse sentido, as proposições de Lev S. Vigotski e seus interlocutores podem contribuir para a instituição ou fortalecimento de um corpo teórico capaz de apoiar a reflexão sobre o conceito de juventude que consiga, sem prejuízo da preponderância cultural sobre o desenvolvimento humano, confrontar as diferentes contribuições.

$\mathrm{Na}$ análise da produção acadêmica dos anos 2007 a 2011 vimos uma abordagem consideravelmente mesclada sobre juventude. Há a presença de alguns estudos com abordagens mais homogêneas de juventude, considerado como um grupo social com posturas intrínsecas, comandadas preponderantemente pelas variáveis biológicas; há a consideração numericamente significativa da idade como um fator determinante da condição juvenil; e os que apresentam a juventude como conceito-processo, algo em movimento constante, independente do peso que as determinações históricas adquiriam no construto epistemológico (Trancoso, 2012).

Podemos evidenciar que os autores das produções analisadas definem juventude como:

1. Um conceito em movimento e que se amplia, mas que necessita ser definido de forma rigorosa para possibilitar, dentre outras coisas, a pesquisa acadêmica e a aplicabilidade de políticas públicas específicas. É uma construção sociocultural, que adquire papeis culturalmente definidos e é alvo de expectativas distintas, de acordo com o contexto cultural em que se desenvolve. Porém, as demarcações biológicas e psíquicas decorrentes estabelecem um padrão de desenvolvimento físico e emocional que dão homogeneidade ao fenômeno. A família, a escola e as políticas públicas, apesar da perda de força ou mudança de status das duas primeiras na relação com a juventude, ainda funcionam como importantes instâncias socializadoras desse grupo social. Não obstante, ocorre um fenômeno de "socialização" endógena, ou seja, o jovem se socializa no seu próprio grupo juvenil, o que acirra as diferenças geracionais, retirando o lugar do adulto nesse processo.

2. Algo distinto da adolescência, sendo o momento em que a pessoa inaugura seu envolvimento nas questões sociais e políticas da sua comunidade e/ ou da sociedade como um todo, já se encaminhando para a fase adulta, ao contrário da adolescência, em que a pessoa está mais imersa em si mesma, nas transformações que as mudanças biológicas vêm 
causando no corpo e no campo psicológico. Por outro lado, adolescência e juventude se imbricam pelo menos entre a parte final da primeira e a parte inicial da segunda, haja vista a própria delimitação etária que as respectivas legislações fazem: o Estatuto da Criança e do Adolescente estabelece que a pessoa adolescente possua de 12 anos completos a 17 anos incompletos e a Política Nacional de Juventude estabelece que a pessoa jovem possua de 15 anos a 25 ou 29 anos. Legalmente, tem-se cada uma posicionada em dois lugares com suas subjetivações culturalmente produzidas. Essa situação reforça a ideia de que adolescência e juventude são a mesma coisa, sem distinções claras, sendo possível utilizar as duas para se referir às mesmas pessoas, e, em alguns casos, omitir uma ou outra expressão pela opção em demarcar um campo político.

3. Um período de transição entre a infância e a fase adulta, período no qual terá fim o "quase sofrimento" das inconclusões próprias do período. Ao mesmo tempo, é um momento importante em si mesmo, com características próprias que devem ser tomadas em consideração tanto pelos agentes socializadores como pela sociedade como um todo. É um devir que tem no adulto o seu porto seguro, seu destino; mas também um devir descolado de qualquer vínculo com o passado ou o futuro; e ainda um devir como é devir a própria existência humana.

4. Jeito de estar no mundo, não importando as delimitações etárias, físicas, biológicas. Não se está jovem, mas se é, ou se pode ser eternamente, a partir do momento em que os valores atribuídos ao que é ser jovem são consumidos e vivenciados por qualquer um. Está ao alcance de todos. Ao mesmo tempo, é também estar coberto por uma moratória vital, um bônus biológico que tem tempo de acabar e não voltar mais.

5. Terem posturas intrínsecas do ser jovem, advindas da sua condição juvenil, o identificam tanto globalmente, posto que há um ethos jovem, como em uma sociedade específica, posto que as questões culturais, sociais e econômicas é que vão dar os contornos da situação juvenil em uma determinada sociedade. Por um lado, espera-se dos jovens a construção de um mundo melhor, que manifestem o descontentamento com o sistema com a finalidade de modificá-lo. Que afrontem o status quo e, com sua irreverência típica, questionem a sociedade e seus tabus, sua moral e costumes. Por outro lado, não se espera alguma coisa do jovem, ou de qualquer outro grupo social, simplesmente pela sua condição, mas busca-se considerar a complexa relação de forças, influências presentes no contexto social em que os jovens se inserem e as experiências que vivenciam ao longo do trajeto nesse contexto. Para isso, é importante ter uma compreensão sociocultural, pois cada ambiente cultural produzirá seu jovem, e, como produto do seu tempo, os jovens talvez sejam os que mais exploram a capacidade dos bens produzirem sentido. Além disso, deve-se estar atento aos discursos hegemônicos sobre a juventude que se produz para cada período histórico.

Neste exercício de compor o conceito de juventude como um mosaico, tomando a produção acadêmico-científica como o objeto de estudo, podese pensar em elementos de ruptura e permanência no conceito de juventude. Consideramos como rupturas o progressivo fortalecimento da ideia de juventude como conceito em movimento de ampliação, que se estabelece como processo de construção social, histórica e cultural acompanhada de demarcações rigorosas relativas aos usos pragmáticos para definição de um grupo de pesquisa ou de uma população alvo para políticas públicas; a concepção de juvenilização da sociedade, de uma juventude sem fronteiras de nenhuma espécie, transformada em um estado do ser e, por último, a desvinculação dos estudos sobre juventude do caminho dicotômico das análises geracionais ou classistas, com a introdução de outros elementos de análise, que irrompe em um mais amplo espectro de procedimentos de análise do fenômeno (Trancoso, 2012).

Por outro lado, consideramos permanências as demarcações biológicas como estabelecedoras de fronteiras entre as categorias sociais e definidoras dos modos de se estar no mundo; o estabelecimento de características psicológicas próprias para as idades, possibilitando a definição de expectativas mais ou menos padronizadas para o jovem, capazes de definir um ethos de grupo; o reconhecimento de diferenças geracionais evidenciadas pelo fortalecimento da prática de isolamento dos grupos juvenis, produzindo um espaço restrito de interação, mais circunscrito aos próprios jovens; as categorias teóricas da moratória e transição que seguem importantes para a definição de juventude. Por último, a perspectiva pragmática das políticas públicas que permanecem não refletindo as rupturas ocorridas no conceito de juventude em relação à sua vinculação sócio-histórica e ao conceito de identidade processo, permanecendo mais vinculadas às ideias de juventude como crise, por isso alvo de cerceamentos preventivos, e como transição, um tempo passageiro propício para escolhas importantes e definitivas em função da fase adulta, tida como de culminância (Trancoso, 2012).

Esse mosaico conceitual de juventude deve considerar com cuidado, no entanto, a convivência de correntes teóricas distintas, às vezes complementares, outras vezes antagônicas. Por isso, o exercício de 
metassíntese realizado considera inconveniente fazer um mosaico, uma colagem buscando dar unicidade a algo que, nas questões a priori, não se coadunam. No grupo dos documentos analisados, $40 \%$ se propunham a discutir o conceito de juventude. Apresentar e discutir o conceito são posturas fundamentais para se evitar sua redução.

Nas definições propostas pelos autores analisados, a expressão "juventude categoria histórica, social e cultural", em suas múltiplas versões e formas de apresentação, foi a mais utilizada. Dantas (2007), por exemplo, afirma que as juventudes "são construções sociais, são 'classes de idade" que "apesar de possuírem uma base material biológica, têm diversas representações históricas” (p. 29).

A ampliação do conceito e sua heterogeneidade teórica e metodológica incrementam o desafio dos novos estudos sobre juventude e sobre a sociedade contemporânea a partir do fenômeno denominado juvenilização por autores como Dal Molin (2007) e Maia (2007).

Nesse sentido, temos a juvenilização da sociedade contemporânea: uma unicidade de características de condição e de situação juvenil, especialmente a partir da escolha de alguns atributos biológicos do corpo jovem, como, por exemplo, a aptidão para qualquer aventura mediante o vigor físico e a iniciação do uso da sexualidade como um dos mediadores dos relacionamentos com o outro. Essa ideia de juventudesigno nos leva à pergunta: os jovens "juvenilizam" a sociedade ou essa sociedade impõe sobre certa categoria social a exacerbação de um determinado modo de vida, pautado na vontade de que o tempo pare e a existência seja congelada nos anos de maior vigor físico?

Sawaia (2001) fala da instrumentalização do corpo e dos afetos. As pessoas transferem para a posse de determinado conjunto de bens e status o ser jovem. Torna-se mais uma realização individual para o mundo, como uma apresentação teatral espetacular, do que algo fruto da alteridade, da relação com o outro, que produz mais compaixão que piedade, mais felicidade que prazer e alegria, aprisiona mais que liberta.

\section{Considerações finais}

A heterogeneidade do conceito de juventude, fruto do processo sócio-histórico de sua produção, deve ser vista como fenômeno importante e propício à ruptura com perspectivas mais restritivas de juventude, como as que a posicionam em um encadeamento linear rumo ao seu telos, ou as que naturalizam e objetivam as "faixas de idade pelas técnicas sociais e pelas ciências médicas" (Groppo, 2000, p. 59).

Nessa direção, teleológica e naturalizante, não somente a dinâmica da existência humana se vê enquadrada em limites predefinidos como a participação política desse grupo social denominado juventude fica restrita a escolhas secundárias, quando muito, a ratificações ou variações permitidas dos objetos políticos pré-construídos. A heterogeneidade pode estabelecer barreiras para uma cooptação da cultura pelo capital, situação que pode tornar-se potencializadora para a reinvenção de novas possibilidades, formas criativas de intervir corresponsavelmente na ordem política, econômica e social.

As manifestações protagonizadas pelas juventudes no Brasil, mais notadamente em 2013, sem prejuízo às não noticiadas tão intensamente nestes e em outros tempos, denunciam essa realidade heterogênea produzida por pessoas que também são parcialmente fruto dessas interações. São nestes campos de batalha, às vezes literais, que as ideias de juventudes são engendradas, talhadas, não a caneta, mas com e nos próprios corpos, por vezes confirmando os pré-conceitos postos nos front por distintos sujeitos coletivos - mercado, políticas públicas, e outros -, e outras vezes acrescentando elementos novos a este caudaloso fluxo.

É um desafio ao exercício acadêmico de produção de conceitos sobre juventude, especialmente no campo da psicologia social crítica, enxergar o que se passa e traduzir em enunciados promotores de reflexão profunda e elementos de transformação, assim como apontar aos sujeitos concretos que realizam a categoria social da juventude e à sociedade como um todo pistas que contribuam para a possibilidade de um viver integral (Sawaia, 2001).

Spaziro e Resende (2010) trazem a reflexão sobre o fato de o jovem estar escravo da própria liberdade de construir seu próprio futuro. Aquilo que se figura nos discursos como conquista de um processo de luta e resistência das gerações anteriores se converte em algoz, já que a transmissão intergeracional perde seu valor de orientação para o jovem, colocando-o em uma situação de orfandade, tutor de si mesmo, forçado a escolher e a decidir, a modernizar-se indefinidamente (Moura, 2011). Sobre isso, Carrano (2007) alerta que o fato de os jovens possuírem, como qualquer outro grupo social, biografias originais não retira a necessidade de estarem inseridos em processos de socialização que possibilitem se tornarem sujeitos, o que implica a capacidade de articular um projeto de vida. A transmissão geracional torna-se peça chave nessa dinâmica, já que "os grupos juvenis, por si 
só, são espaços insuficientes para a vivência da vida pública" (p. 8).

Também se configura importante uma compreensão libertária do processo identitário, que por vezes tem a juventude atribuída como lócus definitivo para sua conformação. Como aborda Sawaia (1995), identidade pode ser entendida não como "uma substância que se mantém, ao longo de sua existência, imutável e idêntica a si mesma, mas um devir, um processo de confronto entre igualdade e alteridade ou, como define Souza Santos (1994), 'identificações em curso"” (p. 20). O devir é introduzido na questão identitária, inicialmente conceituada como aquilo que é igual em todos, passando depois a ser considerada sob um prisma tridimensional: o que era, é e poderá ser. Dimensões potencialmente intercambiáveis que se relacionam em um movimento dialético, como modificações nas redes de sociabilidade e solidariedade, na forma de uma reposição identitária.

Elementos como crença, etnia e classe podem se converter em norteadores de identidade como maior ou menor grau de aprisionamento, de padronização dessa. No caso da juventude, o presente não pode ser encarado como aparência de um futuro onde habita a redenção: o adulto. A perspectiva do adulto como destino faz do passado um relato, e do presente um estágio com um telos que, ao atingi-lo, se converterá também em relato.

Nessa relação de forças, há que se considerar importantes mecanismos incidindo diretamente sobre a produção de conceitos tácitos de juventude, ou seja, um grupo de conceitos que não possui pensador que reclame sua autoria, ou, se possui, tal conceito forjado acaba sendo subsumido pela capilaridade com a qual a sua apresentação se estabelece no senso comum, influenciando consideravelmente as expectativas e imagens a respeito da juventude e dos jovens.

A partir disso, é oportuno reafirmar Sawaia (2001), no sentido de tornar cada vez mais ativas perspectivas e posturas que subvertam uma ordem mundial homogeneizada de forma a reforçar a ação dominadora do homem sobre o homem, que caminhem na contra mão dos fundamentos epistemológicos e ontológicos do saber constituído que brinca de excluir e incluir, conforme melhor aprouver aos grupos que permanecem no poder nas sociedades contemporâneas.

\section{Agradecimento}

Ao Programa de bolsa CAPES-DS pelo apoio financeiro.

\section{Referências}

Abramo, H. W. (1997). Considerações sobre a tematização social da juventude no Brasil. Revista Brasileira de Educação, 5-6, 25-36.

Abramo, H. W. (2005). O uso das noções de adolescência e juventude no contexto brasileiro. In M. V. Freitas (Org.), Juventude e adolescência no Brasil: referências conceituais (pp. 19-39). São Paulo: Ação Educativa.

Alpizar, L. \& Bernal, M. (2003). La construcción social de las juventudes. Ultima Década, 19, 105-123.

Barbalho, A. (2011). Juventude, cidadania e comunicação. Fronteiras - Estudos Midiáticos, 13(2), 86-93.

Batista, M. I. F. C. S. (2008). A formação do indivíduo no capitalismo tardio: um estudo sobre a juventude contemporânea. Tese de Doutorado, Pontifícia Universidade Católica de São Paulo, São Paulo.

Borges, R. C. P. (2010). Jovem-Aprendiz: os sentidos do trabalho expressos na primeira experiência profissional. Dissertação de Mestrado, Universidade Federal de Santa Catarina, Florianópolis.

Bourdieu, P. A. (1983). "Juventude" é só uma palavra. In P. Bourdieu, Questões de sociologia (M. S. Pereira, Trad., pp. 151-162). Lisboa: Fim de Século.

Carrano, P. (2007). Educação de Jovens e Adultos e juventude: o desafio de compreender os sentidos da presença dos jovens na escola da "segunda chance". Reveja-Revista de Educação de Jovens e Adultos, 1, 55-67.

Dal Molin, F. (2007). Redes sociais e micropolíticas da juventude. Tese de Doutorado, Universidade Federal do Rio Grande do Sul, Porto Alegre.

Dantas, M. C. C. (2007). "Vale à pena ver de novo": juventude, escola e televisão. Dissertação de Mestrado, Universidade Federal da Bahia, Salvador.

Feixa, C. \& Leccardi, C. (2010). O conceito de geração nas teorias sobre juventude. Sociedade e Estado, 25(2), 185-204.

Furiati, N. M. A. (2010). Juventude e Estado no Brasil: a lógica constitutiva do Conselho Nacional da Juventude do governo Lula. Tese de Doutorado, Universidade de Brasília, DF.

Gorczevski, D. (2007). Micropoliticas da juventude e visibilidades transversais: in(ter)venções audiovisuais na Restinga, em Porto Alegre. Tese de Doutorado, Universidade do Vale do Rio dos Sinos, Porto Alegre, RS.

Groppo, L. A. (2000). Juventude: ensaios sobre sociologia e história das juventudes modernas. Rio de Janeiro: DIFEL.

Kafrouni, R. (2009). A dimensão subjetiva da vivência de jovens em um programa social - contribuições à análise das políticas públicas para a juventude. Tese de Doutorado, Pontifícia Universidade Católica de São Paulo, São Paulo.

Lei $n$. 11.129, de 30 de junho de 2005. (2005, 01 de julho). Cria o Conselho Nacional da Juventude e a Secretaria Nacional da Juventude. Diário Oficial União, seção 1.

León, O. D. (2005). Adolescência e juventude: das noções às abordagens. In M. V. Freitas (Org.), Juventude e adolescência no Brasil: referências conceituais (pp. 9-18). São Paulo: Ação Educativa.

Maia, A. A. R. M. (2007). Ninguém pode ficar parado: juventude, trabalho e projetos de vida. Dissertação de Mestrado, Universidade do Estado do Rio de Janeiro, Rio de Janeiro.

Mannheim, K. (1961). Diagnóstico do nosso tempo. Rio de Janeiro: Zahar. 
Meneses, B. M. (2007). Juventude, trabalho e formação: um estudo com jovens das camadas populares. Tese de Doutorado, Pontifícia Universidade Católica de São Paulo, São Paulo.

Moura, B. A. (2011). Juventude e trabalho: considerações sobre a situação dos estagiários da Universidade de Brasília. Composição, 5(8), 3-22.

Oliveira, A. A. S. \& Sawaia, B. B. (2009). A infância experienciada em comunidades litorâneas. In H. A. L. Leitão \& A. A. S. Oliveira (Orgs.), Infância e juventude na contemporaneidade: ouvindo os protagonistas (pp. 51-80). Maceió: EDUFAL.

Pais, J. M. (1990). A construção sociológica da juventude: alguns contributos. Análise Social, Lisboa, 25(105-106), 139-166.

Pino, A. (2005). As marcas do humano: às origens da constituição cultural da criança na perspectiva de Lev $S$. Vigotski. São Paulo: Cortez.

Prata, P. H. P. (2009). Comunicação e cidade: juventude e pirataria como exercício de cidade cultural. Dissertação de Mestrado, Universidade do Estado do Rio de Janeiro, Rio de Janeiro.

Sawaia, B. B. (1995). O calor do lugar: segregação urbana e identidade. São Paulo em Perspectiva, 9(2), 20-24.

Sawaia, B. B. (2001). As artimanhas da exclusão: análise psicossocial e ética da desigualdade social ( $2^{\mathrm{a}}$ ed.). Petrópolis, RJ: Vozes.

Souza Santos, B. (1997). A queda do Angelus Novus: para além da equação moderna entre raízes e opções. Novos Estudos CEBRAP, 47, 103-124.

Spaziro, A. M. \& Resende, C. M. A. (2010). Juventude: etapa da vida ou estilo de vida? Psicologia \& Sociedade, 22(1), 4349.

Sposito, M. P. (Org.). (2002). Juventude e escolarização (1980/1998). Brasília: INEP/MEC.

Trancoso, A. E. R. (2012). Juventudes: o conceito na produção científica brasileira. Dissertação de Mestrado, Universidade Federal de Alagoas, Maceió.

Vigotski, L. S. (1996). Teoria e método em psicologia (C. Berliner, Trad.). São Paulo: Martins e Fontes.
Vigotski, L. S. (1999). Pensamento e linguagem (J. L. Camargo, Trad., $2^{\mathrm{a}}$ ed.). São Paulo: Martins e Fontes.

Zanella, A. V. \& Titon, A. P. (2005). Análise da produção científica sobre criatividade em programas brasileiros de pós-graduação em psicologia (1994 - 2001). Psicologia em Estudo, 10(2), 305-316.

Recebido em: 15/06/2013

Revisão em: 01/03/2014

Aceite em: 12/03/2014

Alcimar Enéas Rocha Trancoso é Mestre em Psicologia pela Universidade Federal de Alagoas e doutorando em Educação na mesma universidade. Endereço: Rua Armando de Faria Lobo, 170. Maceió/AL, Brasil. CEP 57042-840. E-mail: osocnart@gmail.com

Adélia Augusta Souto Oliveira é Doutora em Psicologia Social pela Pontifícia Universidade Católica de São Paulo (2005) e estágio de pós-doutorado em Psicologia Social pela Universidad de Barcelona (2011). Professora Associada do Curso de Graduação em Psicologia e do Programa de Pós-Graduação Stricto Sensu em Psicologia da Universidade Federal de Alagoas. Líder do grupo de pesquisa/CNPq: Epistemologia e a ciência psicológica. E-mail: adeliasouto@ip.ufal.br

\section{Como citar:}

Trancoso, A. E. R. \& Oliveira, A. A. S. (2014). Produção social, histórica e cultural do conceito de juventudes heterogêneas potencializa ações políticas. Psicologia \& Sociedade, 26(1), 137-147. 